\title{
Isolation and Chemical Structural Characterisation of a Compound with Antioxidant Activity from the Roots of Senna italica
}

\author{
Matlou Phineas Mokgotho, ${ }^{1}$ Stanley Sechene Gololo, ${ }^{1}$ Peter Masoko, ${ }^{1}$ \\ Ladislaus Kakore Mdee, ${ }^{2}$ Vusi Mbazima, ${ }^{1}$ Leshwene Jeremiah Shai, ${ }^{3}$ \\ Victor Patrick Bagla, ${ }^{1}$ Jacobus Nicolaas Eloff, ${ }^{4}$ and Leseilane Mampuru ${ }^{1}$ \\ ${ }^{1}$ Department of Biochemistry, Microbiology and Biotechnology, University of Limpopo, Turfloop Campus, Private Bag X1106, \\ Sovenga 0727, South Africa \\ ${ }^{2}$ Department of Pharmacy, University of Limpopo, Turfloop Campus, Private Bag X1106, Sovenga 0727, South Africa \\ ${ }^{3}$ Department of Biomedical Sciences, Faculty of Science, Tshwane University of Technology, Private Bag X680, \\ Pretoria 0001, South Africa \\ ${ }^{4}$ Faculty of Veterinary Science, Department of Paraclinical Science, Phytomedicine Programme, University of Pretoria, \\ Onderstepoort, Pretoria 0001, South Africa
}

Correspondence should be addressed to Matlou Phineas Mokgotho; matlou.mokgotho@ul.ac.za

Received 3 April 2013; Revised 22 May 2013; Accepted 23 May 2013

Academic Editor: Mohamed Eddouks

Copyright (C) 2013 Matlou Phineas Mokgotho et al. This is an open access article distributed under the Creative Commons Attribution License, which permits unrestricted use, distribution, and reproduction in any medium, provided the original work is properly cited.

\begin{abstract}
Senna italica, a member of the Fabaceae family (subfamily Caesalpiniaceae), is widely used in South African traditional medicine to treat a number of disease conditions. Aqueous extracts of the plant are mainly used to treat sexually transmitted infections and intestinal complications. The roots of $S$. italica were ground to a fine powder and sequentially extracted with $n$-hexane, dichloromethane, acetone, and methanol using serial exhaustive extraction (SEE) method. Thin layer chromatography was used to analyse the phytochemical composition of the extracts and DPPH radical scavenging method to detect the presence of antioxidant compounds. The bioassay guided fractionation of the acetone fraction afforded an antioxidant compound with free radical scavenging activity. The isolated compound was subsequently identified as 3,4',5-trihydroxystilbene (resveratrol). This study represents the first report of the stilbene resveratrol in S. italica.
\end{abstract}

\section{Introduction}

Plants have formed the basis of sophisticated traditional medicinal systems that have been in existence for thousands of years, and they continue to provide humanity with new remedies [1]. The importance of plants in human and animal health is evident in the increasing presence of natural product drugs in modern medicine. Indeed, natural products and their derivatives represent more than $50 \%$ of all the drugs in clinical use in the world today. During the last 40 years, at least a dozen potent drugs have been derived from flowering plants. One example is that of diosgenin, a drug template derived from Dioscorea species and used to synthesise contraceptive agents [2]. Other examples include anticancer agents derived from Catharanthus roseus as well as laxative agents from Cassia species [1].

The current advancement in science has made it possible for the isolation of compounds of medical importance from plants that are used in traditional medicinal practices. Different parts of plants such as leaves, roots, stems barks and rhizomes are often extracted using different solvents. In most cases, extracts have been shown to be biologically active both in the in vitro and in vivo test systems [3]. Some plant-derived compounds are effective in combination with others, while others are active as single entities [4]. However, the isolation of compounds remains a challenging and 
a mammoth task. Conventionally, the isolation of bioactive compounds is preceded by the determination of the presence of such compounds within plant extracts through a number of bioassays.

Senna italica, a member of the Fabaceae family (subfamily Caesalpinaceae), is known for its therapeutic properties in African folk medicine. Some Senna species from Venda in South Africa are used to treat sexually transmitted infections (STIs) while others are considered to possess significant antibacterial activities [5]. In the northern parts of the Limpopo province of South Africa, S. italica is indicated for the treatment of STIs [6]. A literature survey on the chemical constituents of the genus Senna revealed the presence of alkaloids, quinines, and anthraquinones. These types of compounds have been isolated from heartwood, seeds, root bark, roots, and leaves of the genus Senna [7]. Other studies have reported the isolation of many other compounds including betasitosterol, stigmasterol, and amyrin from the aerial parts of $S$. italica [8]. We have previously reported the antibacterial effect of the acetone extract of $S$. italica on selected bacterial strains, total phenolic content as well as its effect on cancerous Jurkat T cell [9]. Based on these findings, S. italica was further investigated with the aim of identifying the compound(s) that exerted the observed biological activities. Antioxidant compounds are important in the prevention or treatment of various human diseases. Undeniably, reports abound that link free radical scavenging potential and other biological benefits of antioxidant compounds [10]. We here report the isolation of resveratrol, a compound with antioxidant activity, from the acetone root extract of Senna italica through bioassay-guided fractionation.

\section{Materials and Method}

2.1. Extraction. The roots of Senna italica were collected from Bolahlakgomo village (Zebediela subregion, Limpopo province, South Africa). A voucher specimen (UNIN11129) has been deposited in the Larry Leach herbarium of the University of Limpopo. The roots were dried at room temperature and subsequently milled to a fine powder using a grinder (ML 90L4, Monitoring and Control Laboratories (Pty) Ltd., RSA). The milled material (700 g) was serial exhaustively extracted using $n$-hexane, dichloromethane (DCM), acetone and methanol $(\mathrm{MeOH})$ as extractants. The extraction process was repeated three times with 2 litres of each solvent. The extracts were filtered through a Whatman no. 3 filter paper and the filtrates concentrated using a rotary evaporator (Büchi Labotec rotavapor model R-205, Germany). The concentrated extracts were then transferred into preweighed beakers, dried under a stream of cold air, and weighed to determine the resultant mass.

2.2. Free Radical Scavenging Activity. The presence of antioxidant constituents in the various extracts was determined using the method of [11]. Thin layer chromatographic plates were prepared and spotted with the different extracts and eluted in solvents systems of varying polarity, namely, ethyl acetate/methanol/water (EMW) (40:5.4:5) (polar/neutral); chloroform/ethyl acetate/formic acid (CEF) (5:4:1) (intermediate polarity/acidic); benzene/ethanol/ammonium hydroxide (BEA) $(90: 10: 1)$ (nonpolar/basic). For the determination of antioxidant activity, the plates were sprayed with 0.2\% 2,2-diphenyl-1-picryl-hydrazyl (DPPH) (Sigma) in methanol as an indicator. A positive reaction is indicated by the appearance of a yellow spot against a purple background.

2.3. Fractionation. The acetone extract had constituents with antioxidant activity and was thus chosen for further fractionation with $\mathrm{CHCl}_{3}: \mathrm{MeOH}$ of increasing gradient polarity, starting with $100 \% \mathrm{CHCl}_{3}$ to $100 \% \mathrm{MeOH}$. A $460 \mathrm{mg}$ sample of acetone extract was fractionated (Figure 1) into seven fractions of $\mathrm{CHCl}_{3}: \mathrm{MeOH}$ in the following ratios: $1: 0,9: 1,8: 2$, $7: 3,1: 1,3: 7$, and $0: 1(\mathrm{v} / \mathrm{v})$ using column chromatography packed with silica gel $60(63-200 \mu \mathrm{m})$. Following elution, the antioxidant constituents of the resultant fractions were qualitatively evaluated using the TLC-DPPH method described above. The fraction that eluted with 9:1 $\left(\mathrm{CHCl}_{3}: \mathrm{MeOH}\right.$ $(9: 1))$ was found to contain the major compound with antioxidant activity. Hence, the fraction was chosen for further purification of the target compound.

\subsection{Elution and Structural Characterisation of the Antioxidant Compound. Several mobile phases were tested and fraction F9: 1 was better resolved with $\mathrm{CHCl}_{3}$ : EtAOC (1:1). The 9:1 $(125 \mathrm{mg})$ was subjected to a silica gel 60 column chromatog- raphy using $\mathrm{CHCl}_{3}: \mathrm{MeOH}(4: 1)$ as the eluent. Fractions 13- 18 were subjected to chromatography using $\mathrm{CHCl}_{3}: \mathrm{MeOH}$ $(9: 1)$ as eluent. After recrystallisation, a $13 \mathrm{mg}$ of the pure compound was obtained. The compound was dissolved either in methanol, chloroform, or dimethyl sulfoxide depending on its solubility for analysis. The structure of the isolated com- pound was elucidated from the data obtained from ${ }^{1} \mathrm{H}$ - and ${ }^{13} \mathrm{C}-\mathrm{NMR}$ spectra.}

\section{Results}

Different solvents, depending on their polarity, extract varying quantities of components in crude plant material that may be beneficial or harmful to biological systems. $n$-Hexane, for instance, extracts waxes, fats, and fixed oils while acetone extracts alkaloids, aglycones, and glycosides. On the other hand, methanol extracts sugars, amino acids, and glycosides while DCM will commonly extract alkaloids, aglycones, and volatile oils. For these reasons, plant material was extracted using solvent of varying polarity, namely, hexane, DCM, acetone, and methanol. An increase in the extracted material was observed as the polarity of the extracting solvent increased (Table 1). Methanol extract had the highest percent yield followed by DCM, hexane and acetone yielded the least.

Extracted materials were spotted on TLC plates and eluted in BEA, EMW, and CEF and thereafter sprayed with vanillin-sulphuric acid. The free radical scavenging activity of the extracts was determined using the DPPH assay. The yield of the methanol extract did not correlate with the presence of antioxidant constituents in the extract. Although acetone extracts yielded the least, more active constituents were 


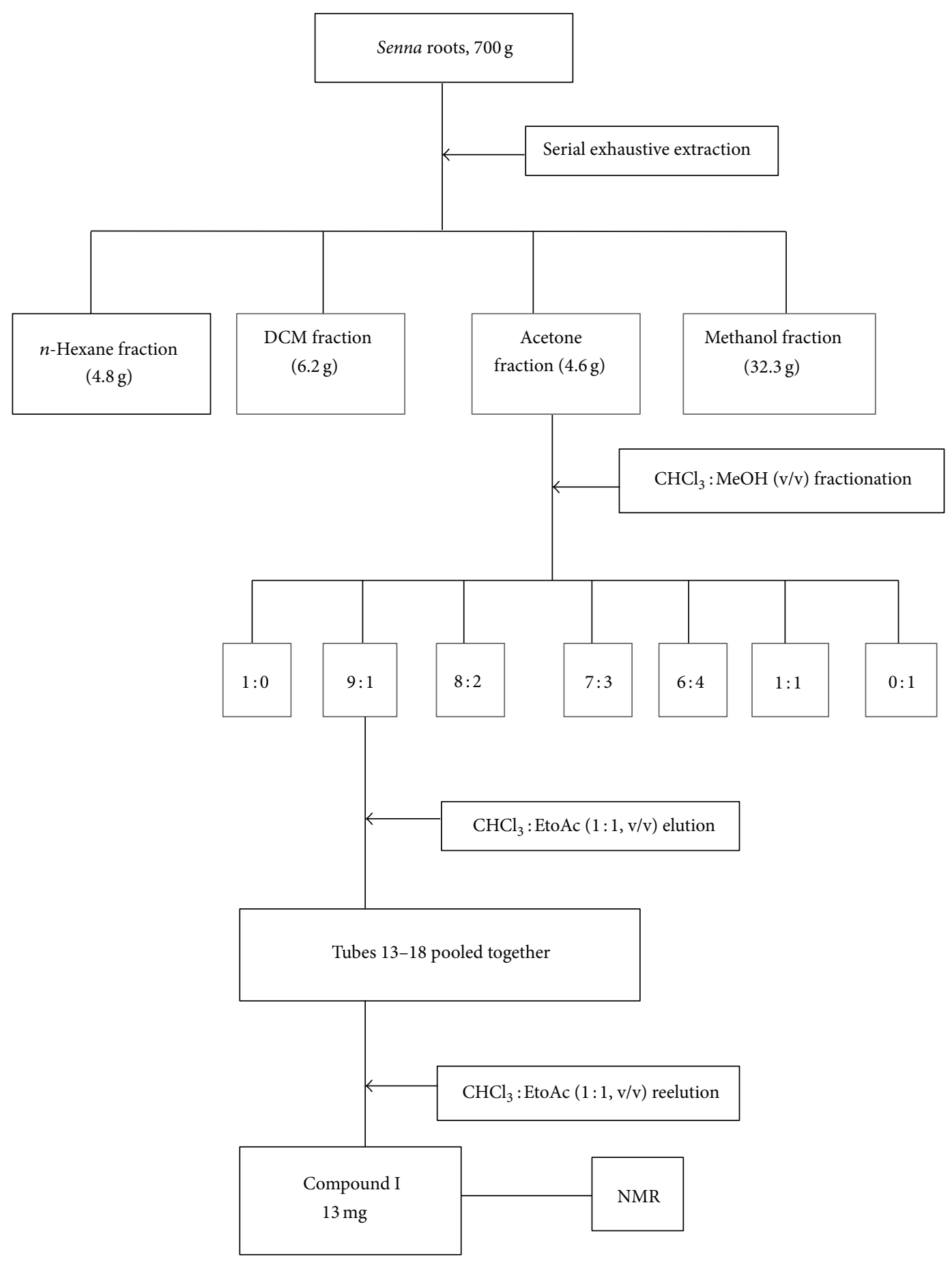

FIGURE 1: Schematic representation of fractionation of acetone extracts of S. italica.

present in these extracts with strong antioxidant activity. This may possibly be related to the ability of acetone to extract both polar and nonpolar constituents. Since acetone extract demonstrated a superior free radical scavenging activity, it was thus chosen for further purification. The extract was fractionated with the gradient solutions of $\mathrm{CHCl}_{3}: \mathrm{MeOH}$ of different ratios. Fraction $8: 2$ gave the highest yield $(237 \mathrm{mg})$ followed by fraction $9: 1(125 \mathrm{mg})$, with fraction $0: 1$ giving the lowest yield (14 mg) as shown (Table 2). Fractions $8: 2$ and 9:1 contained appreciable amounts of vanillin-reacting compounds than the other fractions, with fraction $9: 1$ showing prominent antioxidant activity than the rest (data not included). Thus, fraction 9:1 was selected for further purification. 


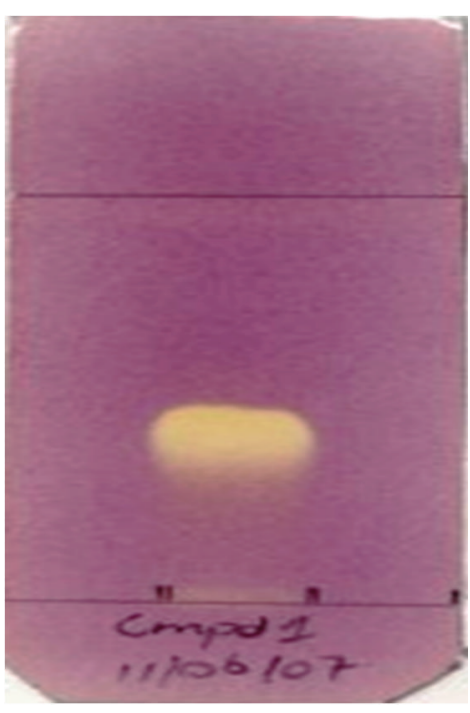

(a)

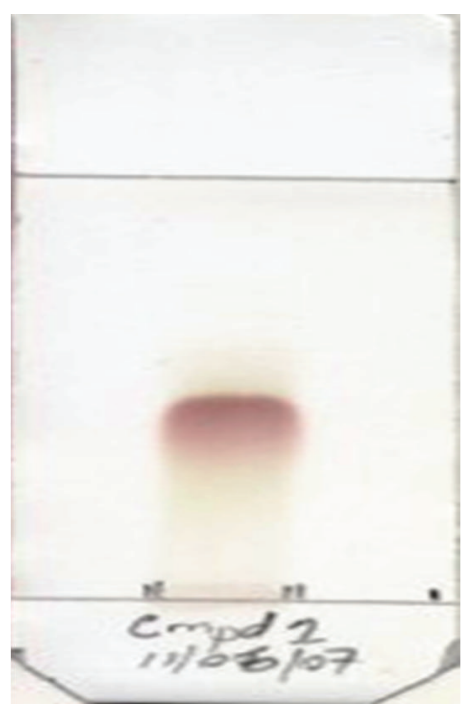

(b)

FIGURE 2: TLC plate of isolated compound sprayed with DPPH (a) and isolated compound sprayed with vanillin-sulphuric acid reagent (b). The plates were developed in $\mathrm{CHCl}_{3}:$ EtOAc $(1: 1, \mathrm{v} / \mathrm{v})$ as the mobile phase. A positive reaction is indicated by the appearance of a yellow spot against a purple background.

TABLE 1: Yields following serial exhaustive extraction of root material of Senna italica with $n$-hexane, DCM, acetone, and $\mathrm{MeOH}$.

\begin{tabular}{lccc}
\hline Extract solvent & Yield $(\mathrm{g})$ & Total yield (g) & Yield (\%) \\
\hline Hexane 1 & 2.8 & & \\
Hexane 2 & 1.3 & 4.8 & 0.69 \\
Hexane 3 & 0.7 & & \\
\hline DCM 1 & 3.5 & & 0.89 \\
DCM 2 & 1.5 & 6.2 & \\
DCM 3 & 1.2 & & 0.66 \\
\hline Acetone 1 & 2.3 & & \\
Acetone 2 & 1.4 & 4.6 & 4.6 \\
Acetone 3 & 0.9 & & \\
\hline MeOH 1 & 17.9 & & \\
MeOH 2 & 8.5 & 32.3 & \\
MeOH 3 & 5.9 & & \\
\hline
\end{tabular}

A suitable mobile phase for elution of the bioactive compound was obtained by comparison of the separated compounds attained from the various ratios of $\mathrm{CHCl}_{3}: \mathrm{MeOH}$ solution used. The $\mathrm{CHCl}_{3}: \mathrm{MeOH}$ ratio of $1: 1(\mathrm{v} / \mathrm{v})$ gave a better separation of the active compound. The $9: 1$ fraction of the acetone extract was then subsequently eluted with $\mathrm{CHCl}_{3}: \mathrm{MeOH}(1: 1, \mathrm{v} / \mathrm{v})$ through a silica gel column. Tubes containing similar compounds noted on TLC fingerprint were pooled together and reeluted with $\mathrm{CHCl}_{3}: \mathrm{MeOH}(1: 1$, $\mathrm{v} / \mathrm{v})$ through a silica gel column. The reelution of the fraction obtained from the pooled tubes gave yield to a pure compound with a positive free radical scavenging activity evident by a yellow spot against a purple background on TLC following spraying with DPPH (Figure 2). The structure of the isolated compound was elucidated (Figure 3) from the data
TABLE 2: Fractionation of the acetone root extract $(700 \mathrm{mg})$ with $\mathrm{CHCl}_{3}: \mathrm{MeOH}$ different ratios on silica gel chromatography.

\begin{tabular}{lcccc}
\hline Systems & $\begin{array}{c}\mathrm{CHCl}_{3} \\
(\%)\end{array}$ & $\begin{array}{c}\mathrm{MeOH} \\
(\%)\end{array}$ & Solvent quantity (mL) & Yield (mg) \\
\hline A & 100 & - & 500 & 58 \\
B & 90 & 10 & 700 & 125 \\
C & 80 & 20 & 1200 & 237 \\
D & 70 & 30 & 500 & 30 \\
E & 50 & 50 & 600 & 25 \\
F & 30 & 70 & 500 & 16 \\
G & - & 100 & 600 & 14 \\
\hline
\end{tabular}

obtained from ${ }^{1} \mathrm{H}$ - and ${ }^{13} \mathrm{C}-\mathrm{NMR}$ spectra and those obtained from the literature $[12,13]$ (Table 3 ).

Compound 1 was obtained as a white powder that was positive to $\mathrm{FeCl}_{3}$ test which indicates the presence of phenolic group. In the $1 \mathrm{H}-\mathrm{NMR}$ spectrum, the coupling patterns between $\delta 7.43(2 \mathrm{H}, \mathrm{d}, \mathrm{J}=9.0 \mathrm{~Hz})$ and $6.86(2 \mathrm{H}, \mathrm{d}, \mathrm{J}=9.0 \mathrm{~Hz}$, and $\delta 6.55(2 \mathrm{H}$, brs $)$ and $6.16(1 \mathrm{H}, \mathrm{brs})$ showed the typical resveratrol skeleton [14]. The coupling constant $(J=18.0 \mathrm{~Hz})$ between $\mathrm{H}-7(\delta 6.89,1 \mathrm{H}, \mathrm{d})$ and $\mathrm{H}-8(\delta 7.03,1 \mathrm{H}, \mathrm{d})$ implied that the configuration of compound 1 was in a trans form configuration. In the ${ }^{13} \mathrm{C}-\mathrm{NMR}$ spectrum, three oxygenated aromatic carbons $(\delta 159.6(\times 2)$ and 158.2) and eleven sp2 carbons (102.7 140.9) were shown. From these data and those presented in Table 3, compound 1 was identified as transresveratrol $[12,13]$. 
TABLE 3: ${ }^{13} \mathrm{C}$ NMR data of isolated compound $(300 \mathrm{MHz}$, acetone$\mathrm{d}_{6}$ ).

\begin{tabular}{lcc}
\hline C number & Literature data & Isolated compound data \\
\hline 1 & 141.3 & 140.9 \\
2 & 105.8 & 105.7 \\
3 & 159.7 & 159.6 \\
4 & 102.7 & 102.7 \\
5 & 159.7 & 159.6 \\
6 & 105.8 & 105.7 \\
7 & 129.4 & 129.1 \\
8 & 127.0 & 126.9 \\
$1^{\prime}$ & 130.4 & 130.0 \\
$2^{\prime}$ & 128.8 & 128.7 \\
$3^{\prime}$ & 116.5 & 116.4 \\
$4^{\prime}$ & 158.4 & 158.2 \\
$5^{\prime}$ & 116.5 & 116.4 \\
$6^{\prime}$ & 128.8 & 128.7 \\
\hline
\end{tabular}

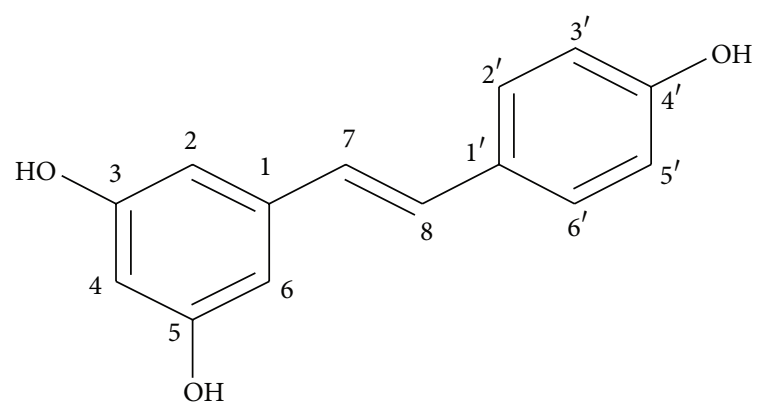

FIgURE 3: The compound identified as $3,4^{\prime}, 5$-trihydroxystilbene $\left(\mathrm{C}_{14} \mathrm{H}_{12} \mathrm{O}_{3}\right)$ from ${ }^{1} \mathrm{H}$ - and ${ }^{13} \mathrm{C}$-NMR spectra peak assignment.

\section{Discussion and Conclusion}

Plant parts such as roots, leaves, stems, and rhizomes possess a myriad of chemical constituents that are biologically active against various disease conditions [3]. In this study, solvents of varying polarity were used in the extraction procedure in an attempt to accommodate the range of polarities of compounds obtained from the roots of $S$. italica.

Methanol extract had the highest yield. The high extract yield obtained with methanol extract could be related to the ability of the solvent to extract compounds of varying polarity [15]. All solvents extracted vanillin-reactive compounds from the roots of $S$. italica. The phytochemical constituents of the extracts were best separated in the intermediate/polar mobile phase, ethylacetate/methanol/water (EMW: $40: 5.4: 5$ ), which separates polar and neutral compounds. Acetone extracts showed the presence of antioxidant compounds which were better separated in the intermediate mobile phase (CEF). The free radical scavenging activity demonstrates the hydrogen donating ability on reaction to the stable free radical which results in the decolouration of the DPPH free radical from purple to yellow [16].
A literature survey on the chemical constituents of the genus Senna revealed the presence of alkaloids, quinines, and anthraquinones that are mainly polar-based compounds [17]. Resveratrol is a natural polyphenolic compound found in a number of edible plants, especially grapes and peanuts, and has been found to exist in both the cis and trans isomeric forms. Although the nutritional value and biological activity of resveratrol have been well documented [18], its oligomers are commonly reported to occur in plants belonging to families such as Dipterocarpaceae, Vitaceae, Cyperaceae, Gnetaceae, Welwitschiaceae, Umbelliferae, and Leguminosae $[19,20]$. This study represents the first isolation of trans resveratrol from the roots of Senna italica belonging to the family Fabaceae. The biological effects of resveratrol together with its well-known antioxidant properties are beneficial for the prevention of several diseases. Findings in our previous study [9] showed the presence of substances in the acetone root extract of $S$. italica with antioxidant, antibacterial, and antiproliferative activities while other studies have also confirmed the antiproliferative effect of resveratrol [21]. The presence of resveratrol may possibly explain the observed effect of the acetone crude extracts on cancerous Jurkat $\mathrm{T}$ cells in our previous studies [9] and may be the major contributors to biological activity observed in that study.

Structural activity relationships of the antioxidant potential of resveratrol from other studies suggest that the hydroxyl group in $4^{\prime}$ position is not the sole determinant for antioxidant activity. It has also been suggested that the presence of $4^{\prime}-\mathrm{OH}$ together with its stereoisomer in the transconformation ( $4^{\prime}$-hydroxystyryl moiety), is a significant prerequisite in its ability to inhibit cell proliferation [21]. The presence of resveratrol in S. italica and the observed antioxidant effect could possibly give more credence to its traditional use in treating various ailments in the Limpopo Province of South Africa [5, 6]. Further studies will focus on the antidiabetic properties of the isolated compound.

\section{Conflict of Interests}

The authors declare no conflict of interests.

\section{Acknowledgments}

The National Research Foundation (NRF) South Africa (Gun no. N710), the Department of Biochemistry, Microbiology and Biotechnology, University of Limpopo, and Phytomedicine Programme, University of Pretoria, are acknowledged for the financial and technical support. M. P. Mokgotho is a recipient of NRF funding under the Thuthuka-CSPG.

\section{References}

[1] A. Gurib-Fakim, "Medicinal plants: traditions of yesterday and drugs of tomorrow," Molecular Aspects of Medicine, vol. 27, no. 1, pp. 1-93, 2006.

[2] A. Sala, M. Del Carmen Recio, R. M. Giner et al., "Anti-inflammatory and antioxidant properties of Helichrysum italicum," Journal of Pharmacy and Pharmacology, vol. 54, no. 3, pp. 365371, 2002. 
[3] B. Van Wyk and M. Wink, Medicinal Plants of the World, Briza Publications, 2004.

[4] M. J. Balunas and A. D. Kinghorn, "Drug discovery from medicinal plants," Life Sciences, vol. 78, no. 5, pp. 431-441, 2005.

[5] T. E. Tshikalange, J. J. M. Meyer, and A. A. Hussein, "Antimicrobial activity, toxicity and the isolation of a bioactive compound from plants used to treat sexually transmitted diseases," Journal of Ethnopharmacology, vol. 96, no. 3, pp. 515-519, 2005.

[6] L. J. Shai, P. Masoko, M. P. Mokgotho et al., "Yeast alpha glucosidase inhibitory and antioxidant activities of six medicinal plants collected in Phalaborwa, South Africa," South African Journal of Botany, vol. 76, no. 3, pp. 465-470, 2010.

[7] F. G. Barbosa, M. D. C. F. De Oliveira, R. Braz-Filho, and E. R. Silveira, "Anthraquinones and naphthopyrones from Senna rugosa," Biochemical Systematics and Ecology, vol. 32, no. 3, pp. 363-365, 2004.

[8] N. H. El-Sayed, A. M. A. Dooh, S. A. M. El-Khrisy, and T. J. Mabry, "Flavonoids of Cassia italica," Phytochemistry, vol. 31, no. 6, p. 2187, 1992.

[9] P. Masoko, S. S. Gololo, M. P. Mokgotho, J. N. Eloff, R. L. Howard, and L. J. Mampuru, "Evaluation of the antioxidant, antibacterial, and antiproliferative activities of the acetone extract of the roots of Senna italica (Fabaceae)," African Journal of Traditional, Complementary and Alternative Medicines, vol. 7, no. 2, pp. 138-148, 2010.

[10] Y. Li and M. A. Trush, "Reactive oxygen-dependent DNA damage resulting from the oxidation of phenolic compounds by a copper-redox cycle mechanism," Cancer Research, vol. 54, no. 7, pp. 1895-1898, 1994.

[11] C. Deby and G. Magotteaux, "Relationship between essential fatty acids and tissue antioxidant levels in mice," Comptes Rendus des Seances de la Societe de Biologie et de Ses Filiales, vol. 164, no. 12, pp. 2675-2681, 1970.

[12] M. Guiso, C. Marra, and A. Farina, "A new efficient resveratrol synthesis," Tetrahedron Letters, vol. 43, no. 4, pp. 597-598, 2002.

[13] C. Roat, N. Kumar, and K. G. Ramawat, "Occurrence of stilbenes in unorganized cultures of Cayratia trifolia (L.) Domin," Journal of Herbal Medicine and Toxicology, vol. 2, no. 1, pp. 11-15, 2008.

[14] Y. Lee, S. Kwon, H. Kim et al., "Isolation of oleanane triterpenes and trans-resveratrol from the root of peanut (Arachis hypogaea)," Journal of the Korean Society For Applied Biological Chemistry, vol. 52, no. 1, pp. 40-44, 2009.

[15] J. N. Eloff, "Which extractant should be used for the screening and isolation of antimicrobial components from plants?" Journal of Ethnopharmacology, vol. 60, no. 1, pp. 1-8, 1998.

[16] N.-E. Es-Safi, A. Kollmann, S. Khlifi, and P.-H. Ducrot, "Antioxidative effect of compounds isolated from Globularia alypum L. structure-activity relationship," Food Science and Technology, vol. 40, no. 7, pp. 1246-1252, 2007.

[17] L. Frémont, "Minireview: biological effects of resveratrol," Life Sciences, vol. 66, no. 8, pp. 663-673, 2000.

[18] J. Kawabata, S. Ichikawa, H. Kurihara, J. Mizutani, and A. Kobophenol, "A unique tetrastilbene from Carex Kobomugi Ohwi (Cyperaceae)," Tetrahedron Letters, vol. 30, no. 29, pp. 3785-3788, 1989.

[19] S. Sotheeswaran and V. Pasupathy, "Distribution of resveratrol oligomers in plants," Phytochemistry, vol. 32, no. 5, pp. 10831092, 1993.
[20] O. P. Mgbonyebi, J. Russo, and I. H. Russo, "Antiproliferative effect of synthetic resveratrol on human breast epithelial cells," International Journal of Oncology, vol. 12, no. 4, pp. 865-869, 1998.

[21] L. A. Stivala, M. Savio, F. Carafoli et al., "Specific structural determinants are responsible for the antioxidant activity and the cell cycle effects of resveratrol," Journal of Biological Chemistry, vol. 276, no. 25, pp. 22586-22594, 2001. 


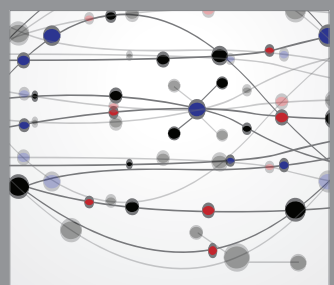

The Scientific World Journal
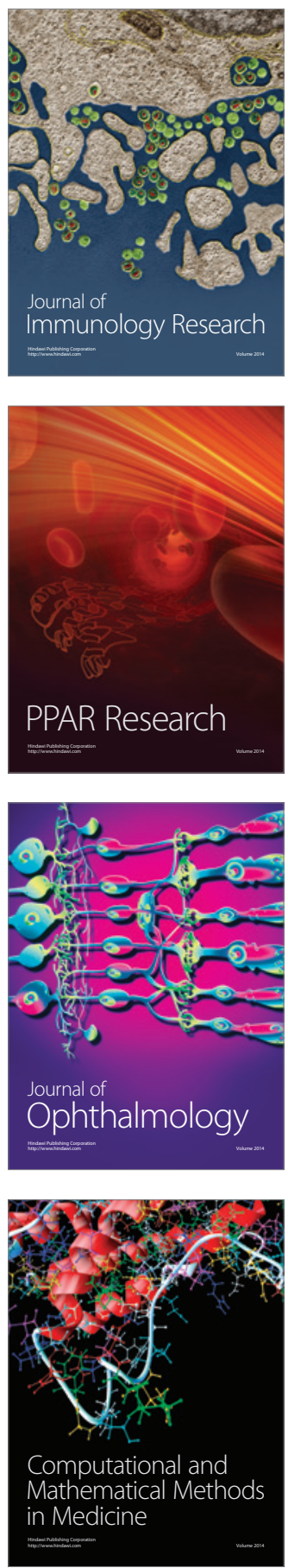

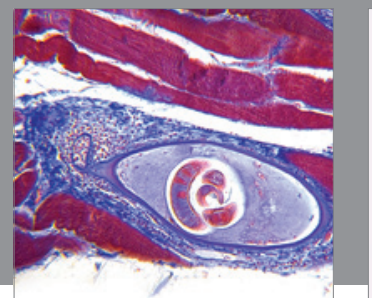

Gastroenterology

Research and Practice
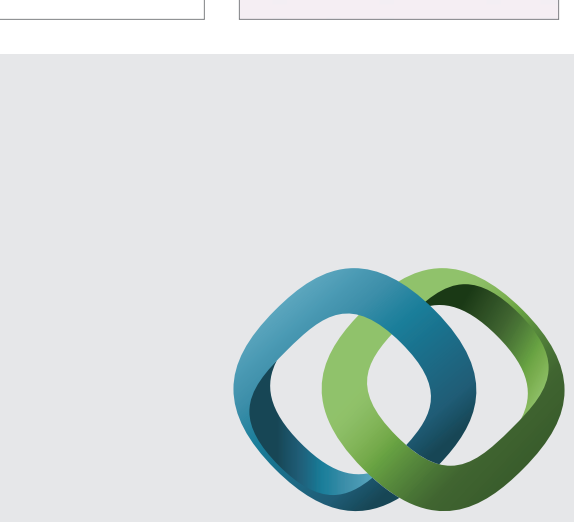

\section{Hindawi}

Submit your manuscripts at

http://www.hindawi.com
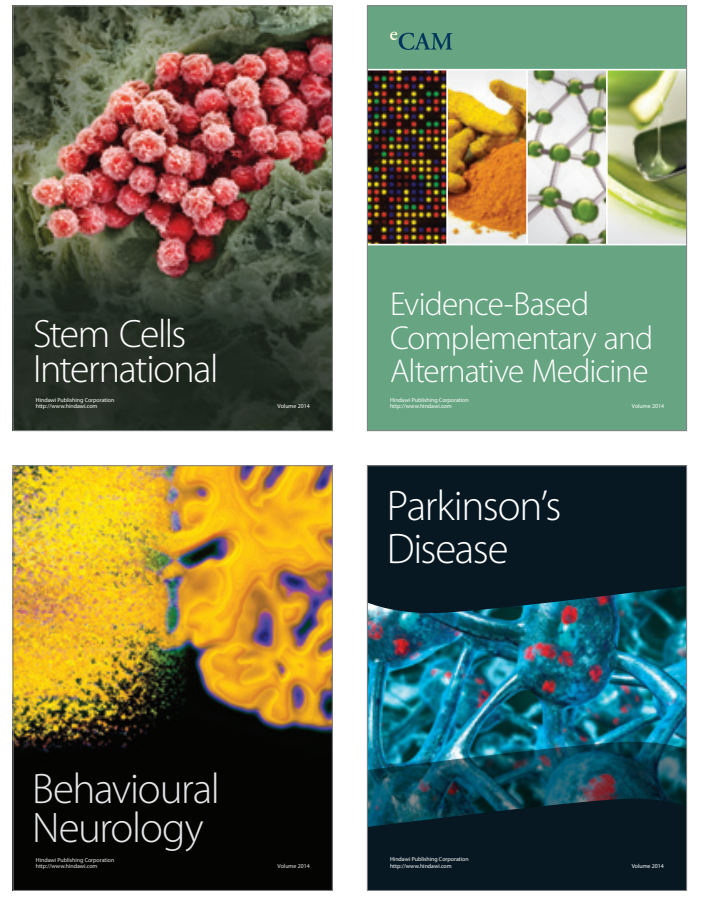
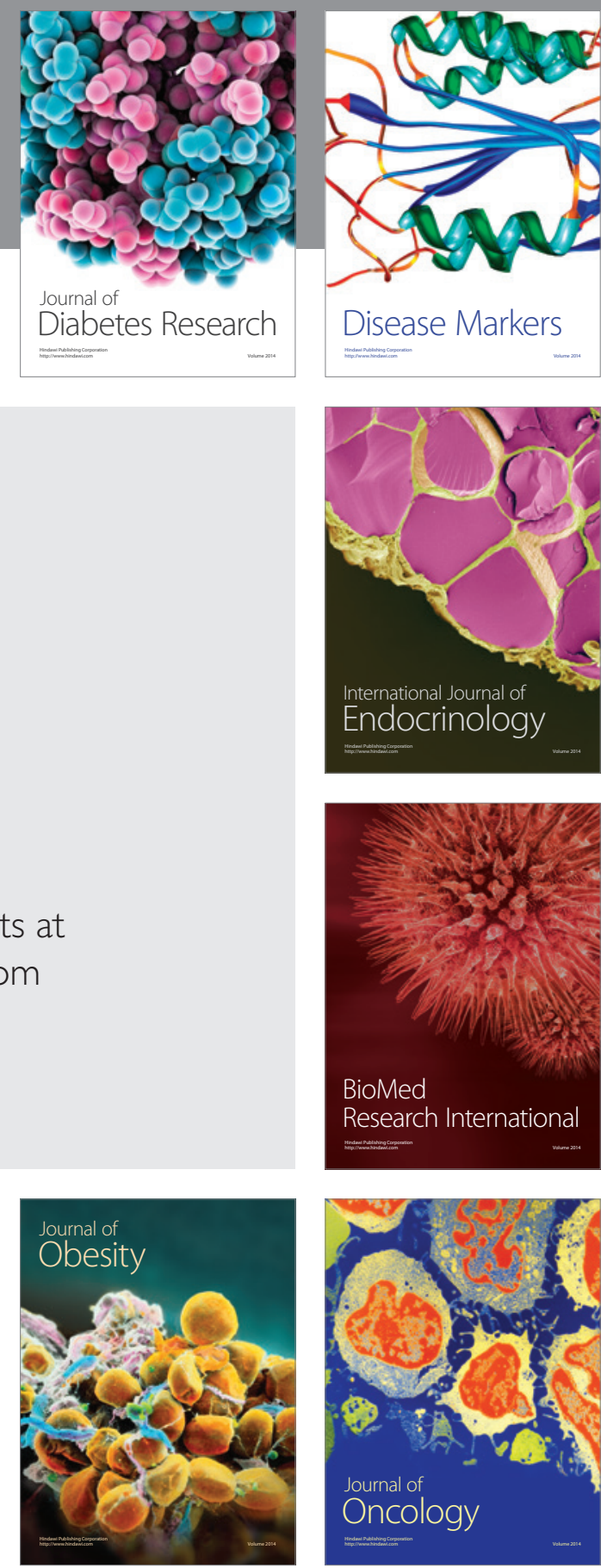

Disease Markers
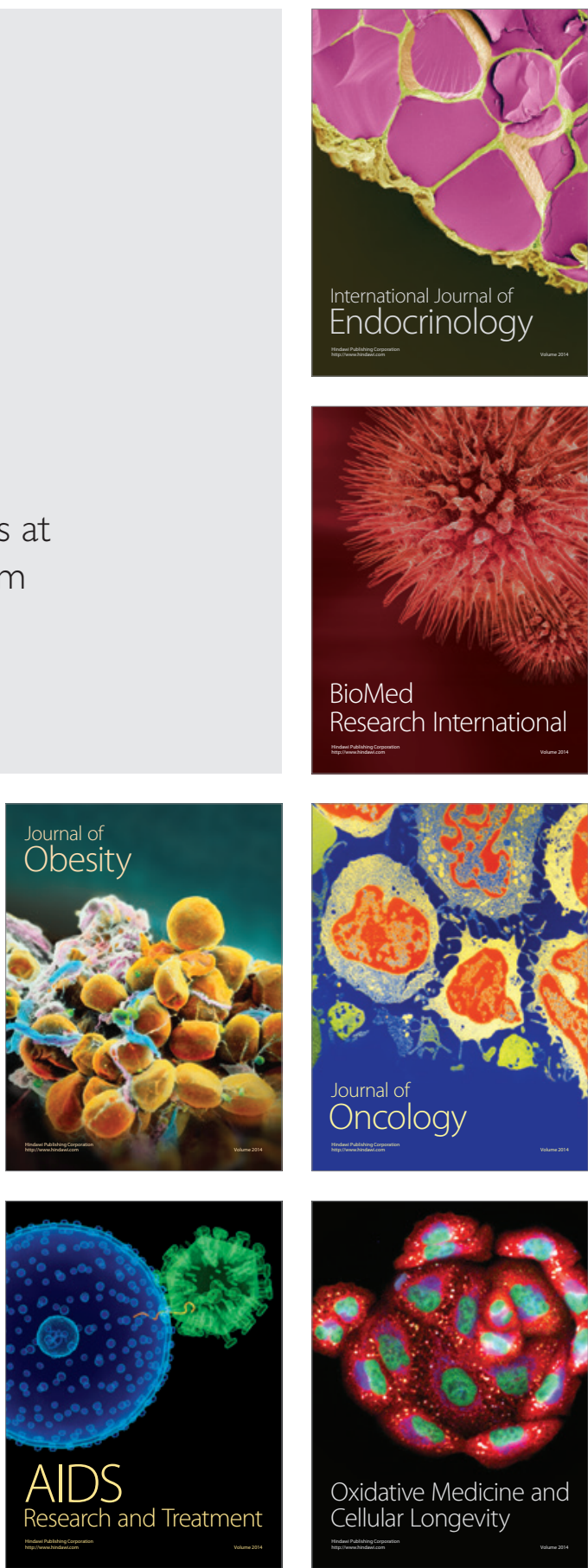